University of Wollongong

Research Online

Faculty of Engineering and Information

Faculty of Engineering and Information

Sciences - Papers: Part A

Sciences

$1-1-2015$

Selection of forward osmosis draw solutes for subsequent integration with anaerobic treatment to facilitate resource recovery from wastewater

\author{
Ashley J. Ansari \\ University of Wollongong, ashleyz@uow.edu.au \\ Faisal I. Hai \\ University of Wollongong, faisal@uow.edu.au \\ Wenshan Guo \\ University of Technology Sydney \\ Hao H. Ngo \\ University of Technology Sydney \\ William E. Price \\ University of Wollongong, wprice@uow.edu.au
}

See next page for additional authors

Follow this and additional works at: https://ro.uow.edu.au/eispapers

Part of the Engineering Commons, and the Science and Technology Studies Commons

Research Online is the open access institutional repository for the University of Wollongong. For further information contact the UOW Library: research-pubs@uow.edu.au 


\title{
Selection of forward osmosis draw solutes for subsequent integration with anaerobic treatment to facilitate resource recovery from wastewater
}

\author{
Abstract \\ Forward osmosis (FO) can be used to extract clean water and pre-concentrate municipal wastewater to \\ make it amenable to anaerobic treatment. A protocol was developed to assess the suitability of FO draw \\ solutes for pre-concentrating wastewater for potential integration with anaerobic treatment to facilitate \\ resource recovery from wastewater. Draw solutes were evaluated in terms of their ability to induce \\ osmotic pressure, water flux, and reverse solute flux. The compatibility of each draw solute with \\ subsequent anaerobic treatment was assessed by biomethane potential analysis. The effect of each \\ draw solute (at concentrations corresponding to the reverse solute flux at ten-fold pre-concentration of \\ wastewater) on methane production was also evaluated. The results show that ionic organic draw solutes \\ (e.g., sodium acetate) were most suitable for FO application and subsequent anaerobic treatment. On the \\ other hand, the reverse solute flux of inorganic draw solutions could inhibit methane production from FO \\ pre-concentrated wastewater.

\section{Disciplines} \\ Engineering | Science and Technology Studies

\section{Publication Details} \\ Ansari, A. J., Hai, F. I.., Guo, W., Ngo, H. H., Price, W. E. \& Nghiem, L. D. (2015). Selection of forward \\ osmosis draw solutes for subsequent integration with anaerobic treatment to facilitate resource recovery \\ from wastewater. Bioresource Technology, 191 30-36.

\section{Authors} \\ Ashley J. Ansari, Faisal I. Hai, Wenshan Guo, Hao H. Ngo, William E. Price, and Long D. Nghiem
}




\title{
Selection of forward osmosis draw solutes for subsequent integration with anaerobic treatment to facilitate resource recovery from wastewater
}

\author{
Revised Manuscript Submitted to

\section{Bioresource Technology}

April 2015
Ashley J. Ansari ${ }^{a}$, Faisal I. Hai ${ }^{a}$, Wenshan Guo ${ }^{b}$, Hao H. Ngo ${ }^{b}$, William E. Price ${ }^{c}$, and Long D. Nghiem ${ }^{\mathrm{a}, *}$

${ }^{\text {a }}$ Strategic Water Infrastructure Laboratory, School of Civil Mining and Environmental

Engineering, University of Wollongong, Wollongong, NSW 2522, Australia

${ }^{\mathrm{b}}$ Centre for Technology in Water and Wastewater, School of Civil and Environmental Engineering, University of Technology Sydney, Sydney, NSW 2007, Australia

${ }^{\mathrm{c}}$ Strategic Water Infrastructure Laboratory, School of Chemistry

University of Wollongong, Wollongong, NSW 2522, Australia

\footnotetext{
* Corresponding author: Long Duc Nghiem; Email: longn@uow.edu.au; Ph +61 242214590
} 


\begin{abstract}
Forward osmosis (FO) can be used to extract clean water and pre-concentrate municipal wastewater to make it amenable to anaerobic treatment. A protocol was developed to assess the suitability of FO draw solutes for pre-concentrating wastewater for potential integration with anaerobic treatment to facilitate resource recovery from wastewater. Draw solutes were evaluated in terms of their ability to induce osmotic pressure, water flux, and reverse solute flux. The compatibility of each draw solute with subsequent anaerobic treatment was assessed by biomethane potential analysis. The effect of each draw solute (at concentrations corresponding to the reverse solute flux at ten-fold pre-concentration of wastewater) on methane production was also evaluated. The results show that organic-based draw solutes (e.g., sodium acetate) were most suitable for FO application and subsequent anaerobic treatment. On the other hand, the reverse solute flux of inorganic draw solutions could inhibit methane production from FO preconcentrated wastewater.
\end{abstract}

Keywords: Forward osmosis; reverse solute flux; biomethane potential (BMP) analysis; draw solute selection; sewer mining. 


\section{Introduction}

The recently recognised value of clean water, energy, and nutrients in municipal wastewater has led to a paradigm shift in urban water management, toward a modern framework that incorporates resource recovery with the traditional sanitation mandate. The value of these resources goes beyond short-term economic outcomes, because long-term human health and environmental benefits can play an even greater role in wastewater management decisions. Water scarcity and environmental pollution have driven water reuse to become an integral function of modern wastewater treatment plants (Shannon et al., 2008). Further efforts to include energy and nutrient recovery are justified by the relationship between the stringency of effluent regulations and energy consumption (Iranpour et al., 1999), as well as concerns for worldwide phosphorus security (Koppelaar \& Weikard, 2013).

Clean water reclamation from municipal wastewater is well established. However, a greater focus is required to further develop energy and nutrient recovery practices. The dilute nature of municipal wastewater is a major obstacle hindering energy and nutrient recovery. Thus, it is necessary to pre-concentrate municipal wastewater by five to ten-fold to achieve the required strength in terms of chemical oxygen demand (COD) for subsequent anaerobic treatment (Verstraete \& Vlaeminck, 2011), through which energy and nutrients can be recovered in the form of biogas (Burn et al., 2013; Nghiem et al., 2014a) and struvite $\left(\mathrm{MgNH}_{4} \mathrm{PO}_{4} \cdot 6 \mathrm{H}_{2} \mathrm{O}\right)$ (Garcia-Belinchón et al., 2013; Xie et al., 2014), respectively. The most common and effective technique to recover nutrients after anaerobic treatment is via struvite precipitation. In this process, magnesium salt addition is required for struvite $\left(\mathrm{MgNH}_{4} \mathrm{PO}_{4} \cdot 6 \mathrm{H}_{2} \mathrm{O}\right)$ formation. However, because of the low ammonia and phosphate concentrations in municipal wastewater, magnesium salt must be added to obtain a concentration well above the stoichiometric ratio to facilitate struvite precipitation. In this instance, the pre-concentration of wastewater will lower the magnesium requirement for struvite formation (McCarty et al., 2011; Xie et al., 2014), thus significantly improving the economics of nutrient recovery (Garcia-Belinchón et al., 2013). The deployment of innovative technologies such as forward osmosis (FO) to pre-concentrate organic matter and nutrients can facilitate anaerobic treatment, thus allowing resource recovery to become economically viable. 
FO is a promising technology for the pre-concentration of wastewater and has recently demonstrated potential for direct sewer mining (Lutchmiah et al., 2011; Xie et al., 2013). When applied directly for wastewater treatment, this concentration driven process has several significant advantages, including a high rejection of contaminants and low fouling propensity compared to pressure driven microfiltration. Therefore, FO can concentrate the organic matter and nutrients in wastewater to a small volume for potential integration with anaerobic treatment to facilitate resource recovery. Furthermore, FO provides robust pre-treatment for reverse osmosis (Hancock et al., 2013) or membrane distillation (Xie et al., 2013) for clean water production.

Reverse solute flux is an inherent phenomenon in FO. When integrating FO with a bioreactor, a major technical challenge is the migration of draw solute into the mixed liquor. This can severely affect the biological performance, particularly of the anaerobic treatment process as inhibitory substances are often the major cause of instability and failure of anaerobic treatment systems (Chen et al., 2008). Inorganic salts are widely used as draw solutes for FO, since they are usually inexpensive, capable of generating high osmotic pressures, and are less likely to induce significant internal concentration polarization (ICP). ICP associated with inorganic salts is small because of their small solute size and rapid diffusion; however, these properties often promote a high reverse solute flux (Shaffer et al., 2015). For example, sodium chloride has a high reverse solute flux, and therefore sodium concentrations are likely to exceed the value known to inhibit anaerobic treatment $(3 \mathrm{~g} \mathrm{Na} / \mathrm{L})$ (Feijoo et al., 1995) during wastewater pre-concentration.

Several draw solutes have been investigated with the intention of avoiding or reducing the effects of reverse solute flux on subsequent biological treatment. Lutchmiah et al. (2014) demonstrated that zwitterionic compounds, such as glycine, have a lower reverse solute flux compared to sodium chloride and the potential to increase the methane yield of concentrated wastewater due to their osmoprotectant properties. Bowden et al. (2012) proposed organic ionic salts as substitute draw solutes in osmotic membrane bioreactors (OMBRs), whereby salt accumulation has detrimental effects on biological performance. Other approaches involve comparing the microbial toxicity of draw solutions (Nawaz et al., 2013) or the longterm operation of alternative draw solutions in OMBRs to evaluate effects (Tang \& $\mathrm{Ng}$, 2014). Nonetheless, no studies have evaluated the potential impact of reverse solute flux on subsequent anaerobic treatment. This is despite the availability of the well-established 
biomethane potential (BMP) test, which can be used to simulate the anaerobic treatment process in batch mode to assess the methane production from different substrates (Koch et al., 2015; Mayer et al., 2014; Nghiem et al., 2014b).

In this study, a draw solute selection protocol was developed for FO systems which are integrated with anaerobic treatment. FO flux performance was assessed based on water flux and reverse solute flux. The effect of reverse solute flux on anaerobic treatment was evaluated by BMP analysis of draw solute-impacted substrate.

\section{Materials and methods}

\subsection{Preliminary draw solution selection protocol}

A literature review of previous FO studies to pre-concentrate wastewater was conducted to select ten draw solutions to undergo experimental assessment. Firstly, organic-based draw solutions that have demonstrated a suitably high water flux and the expectation to have negligible impact on anaerobic treatment were considered. Secondly, inorganic draw solutions with low reverse solute flux were considered and sodium chloride was selected as a reference. OLI Stream Analyzer (OLI Systems, Inc., Morris Plains, New Jersey, USA) was then used to simulate osmotic pressure as a function of draw solution concentration, to verify the suitability for further FO experimental assessment and biological screening.

\subsection{Materials and chemicals}

Cellulose triacetate (CTA) membrane with embedded polyester screen support was acquired from Hydration Technologies Innovation (HTI) (Albany, Oregon, USA). Digested sludge was obtained from a full-scale wastewater treatment plant (Wollongong, Australia) and was used as inoculum for the BMP measurements. All draw solutes used in this study were of analytical grade.

\subsection{Forward osmosis system}

FO experiments were conducted using a lab-scale, cross-flow FO membrane system (Supplementary Data, Figure. S1). The FO membrane cell consisted of two symmetric flow channels each with length, width, and height of 130, 95, and $2 \mathrm{~mm}$, respectively, and an effective membrane area of $123.5 \mathrm{~cm}^{2}$. 
The feed and draw solutions were circulated by two variable speed gear pumps (Micropump, Vancouver, Washington, USA) at $1 \mathrm{~L} / \mathrm{min}$ (corresponding to a cross-flow velocity of $9 \mathrm{~cm} / \mathrm{s}$ ) and was regulated by two rotameters. The working volumes of the feed and draw solution reservoirs were 3 and $2 \mathrm{~L}$, respectively. The draw solution reservoir was positioned on a digital balance (Mettler-Toledo Inc., Hightstown, New Jersey, USA) and weight changes were recorded to determine permeate water flux. For ionic draw solutions, a reservoir containing a highly concentrated solution was also placed on the digital balance and was intermittently dosed into the draw solution to maintain constant osmotic pressure. The conductivity of the draw solution was continuously measured by a conductivity probe (ColeParmer, Vernon Hills, Illinois, USA), which was connected to a controller (control accuracy of $\pm 0.1 \mathrm{mS} / \mathrm{cm}$ ) and a peristaltic pump to automatically regulate the draw solution concentration. For the covalent organic draw solution, concentration was manually controlled by adding the correct volume of highly concentrated solution every $2 \mathrm{~h}$.

\subsection{Forward osmosis assessment}

The flux performance of each draw solution was evaluated by using the lab-scale, cross-flow FO system to determine water flux $\left(J_{w}\right)$ and reverse solute flux $\left(J_{s}\right)$. FO experiments were conducted according to the standard procedure previously described by Cath et al. (2013). Analytical grade solutes were dissolved in DI water at concentrations corresponding to an osmotic pressure of 30 bar. This osmotic pressure was selected for two reasons. Firstly, seawater has an approximate osmotic pressure of 30 bar and could be used as a readily available and inexpensive $\mathrm{NaCl}$ solution. Secondly, higher osmotic pressures were not investigated due to the corresponding increase in draw solute viscosity (particularly for organic and/or high molecular weight solutes) and the expected exacerbation of internal concentration polarization. Each draw solution was tested in FO mode (active layer facing the feed solution) with DI water as the feed solution. Conductivity, $\mathrm{pH}$, and temperature of the feed solution were monitored hourly. For the covalent organic draw solutions, a $20 \mathrm{~mL}$ sample was withdrawn from the feed solution every $2 \mathrm{~h}$ for subsequent total organic carbon (TOC) analysis. All FO experiments were conducted in duplicate and lasted for at least $6 \mathrm{~h}$.

Reverse solute flux selectivity (RSFS) describes the volume of permeate water per gram of solute that has diffused from the draw solution to the feed solution and can be expressed as $J_{w} / J_{s}$. RSFS is important for draw solution selection in terms of replenishment costs, yet 
this parameter can more importantly give an indication of the expected solute concentration in FO concentrate. The draw solute concentration in the pre-concentrated wastewater $\left(C_{f}\right)$ was calculated using Equation 1:

$$
C_{f}=\frac{1}{\left(J_{w} / J_{s}\right)} \cdot \frac{R}{1-R}
$$

where $J_{w} / J_{s}$ is the RSFS observed during the FO performance experiments, and $R$ is the assumed FO system water recovery. Equation 1 is based on the premise that flux decline (due to membrane fouling or an increase in feed solution osmotic pressure) is negligible and that RSFS is constant. A system water recovery of $90 \%$ was used to represent a ten-fold increase in the strength of municipal wastewater by FO pre-concentration. This condition can also be used to represent the worst-case scenario with respect to the impact of draw solutes on potential anaerobic treatment of the pre-concentrated wastewater.

\subsection{Biomethane potential apparatus and protocol}

BMP measurements were conducted to indicate the effect of each draw solute on methane production during anaerobic digestion. The BMP apparatus could simultaneously deploy up to 16 fermentation bottles, which were submerged in a water bath (Ratek Instruments, Boronia, Victoria, Australia) and connected to a biogas collection gallery (Supplementary Data, Figure. S2). The fermentation bottles (Wiltronics Research, Ballarat, Victoria, Australia) were sealed with a rubber bung and submerged in the water bath to maintain a temperature of $35.0 \pm 0.1^{\circ} \mathrm{C}$. An S-shaped air lock and flexible plastic tubing were used to collect the biogas. The biogas collection gallery consisted of an array of inverted $1000 \mathrm{~mL}$ plastic measuring cylinders, which were initially filled with a $\mathrm{NaOH}$ solution $(1 \mathrm{M})$. As biogas was introduced to the cylinder, $\mathrm{CO}_{2}$ and $\mathrm{H}_{2} \mathrm{~S}$ were sequestered by the $\mathrm{NaOH}$ solution, and the remaining $\mathrm{CH}_{4}$ gas displaced the solution inside the cylinder. The volume of $\mathrm{NaOH}$ displaced by $\mathrm{CH}_{4}$ gas was recorded every day. Further details of the BMP testing apparatus are given elsewhere (Nghiem et al., 2014b).

Equation 1 was used to calculate the amount of each draw solute to be added to the digested sludge, to simulate the reverse solute flux accumulation at $90 \%$ water recovery from preconcentrated wastewater. The calculated amount of draw solute was firstly dissolved in 50 $\mathrm{mL}$ of DI water and then mixed with $700 \mathrm{~mL}$ of digested sludge. In the control BMP bottles, 
$50 \mathrm{~mL}$ of DI water was added to the same amount of digested sludge. The BMP bottle was purged with nitrogen gas, sealed, and connected to the gas collection gallery. All BMP experiments including the control were conducted in duplicate. The substrate in each bottle was characterized before and after the BMP experiment in terms of total solids (TS), volatile solids (VS), $\mathrm{pH}$, alkalinity, total chemical oxygen demand $\left(\mathrm{COD}_{\mathrm{t}}\right)$, and soluble chemical oxygen demand $\left(\mathrm{COD}_{\mathrm{s}}\right)$.

\subsection{Analytical methods}

Temperature, $\mathrm{pH}$, and electrical conductivity were measured using an Orion 4-Star Plus $\mathrm{pH} /$ conductivity meter (Thermo Scientific, Waltham, Massachusetts, USA). A Shimadzu TOC analyser (TOC- $\mathrm{V}_{\mathrm{CSH}}$ ) was used to determine the reverse solute flux of covalent organic draw solutions.

For digested sludge characterisation, TS, VS, and alkalinity were measured using standard methods (Eaton et al., 2005). COD was determined using a Hach DBR200 COD Reactor and Hatch DR/2000 spectrophotometer (program number 435 COD HR) following the US-EPA Standard Method $5220 \mathrm{D}$. For $\mathrm{COD}_{\mathrm{s}}$, the sludge supernatant was filtered through a $1 \mu \mathrm{m}$ filter paper and the filtrate was then analysed, whilst $\mathrm{COD}_{t}$ was measured by direct dilution of the homogenised sludge.

\section{Results and discussion}

\subsection{Preliminary draw solution selection}

Ten draw solutes were selected for experimental assessment to represent a range of inorganic and organic compounds. Sodium chloride was selected as a reference and magnesium sulfate was selected due to its reported low reverse solute flux through FO membrane (towards the bioreactor side), causing potentially minimal impact on anaerobic treatment (Achilli et al., 2010). Organic ionic draw solutions, namely sodium acetate, magnesium acetate, and sodium formate, were also selected due to their exhibition of a competitive water flux and potential benefits when combined with biological systems (Bowden et al., 2012). EDTA disodium salt has been previously studied by Hau et al. (2014) for the concentration of wastewater sludge. Neutral organic-based draw solutes, including glucose, glycine, glycerol, and urea, were selected based on their moderate water flux and the anticipation for negligible effects on anaerobic treatment, independent of the magnitude of reverse solute flux (Yong et al., 2012). Glycine has recently been investigated and found to be highly compatible with anaerobic 
digestion (Lutchmiah et al., 2014). Each draw solute had previously shown potential for use as a FO draw solute for wastewater applications.

The molar concentration required to generate 30 bar of osmotic pressure varies significantly between the ten selected draw solutes (Table 1). Overall, the required molar concentration varies from $0.3 \mathrm{M}$ (EDTA disodium salt) to as high as $1.3 \mathrm{M}$ (glycine).

\section{[Table 1]}

\subsection{Forward osmosis flux performance}

\subsubsection{Water and reverse solute flux}

The draw solutions exhibited quite diverse flux performance despite being evaluated at the same osmotic pressure of 30 bar (Figure 1). Glycerol and urea could produce a moderate water flux (3.09 and $1.37 \mathrm{~L} / \mathrm{m}^{2} \mathrm{~h}$, respectively) but the reverse solute fluxes were extremely high (15.2 and $106.3 \mathrm{~g} / \mathrm{m}^{2} \mathrm{~h}$, respectively). These two draw solutions were eliminated from further analysis because the high reverse solute flux would result in excessive accumulation in pre-concentrated wastewater, as well as unsustainable FO operation. The remaining draw solutions exhibited a water flux in the range of 2.18 to $4.11 \mathrm{~L} / \mathrm{m}^{2} \mathrm{~h}$. The observed variation in water flux at the same draw solution osmotic pressure could be attributed to the extent of ICP experienced by each solute (Achilli et al., 2010; Bowden et al., 2012; Zhao \& Zou, 2011). ICP describes the dilution of the draw solution in the membrane support layer which reduces the effective osmotic driving force and is affected by the draw solute kinetic characteristics including diffusivity, viscosity, and ion or molecule size (McCutcheon \& Elimelech, 2006).

\section{[Figure 1]}

Draw solute diffusivity strongly affected water flux (Figure 2a) and reverse solute flux (Figure 2b). Water flux was linearly correlated to diffusion coefficient and clearly represented the extent of dilutive ICP for each solute. Solutes with low diffusivity experienced severe ICP and were more likely to display a low water flux. On the other hand, highly-mobile solutes could reduce the effects of ICP, and thus had a high water flux. This result is in good agreement with ICP theory, as within the relevant range, solutes with higher diffusion coefficients can produce a larger water flux at a constant bulk draw solution osmotic pressure (McCutcheon \& Elimelech, 2006; Shaffer et al., 2015). The results also show that reverse solute flux tended to increase exponentially for solutes with higher 
diffusion coefficients (Figure 2b). Thus, a trade-off exists between selecting highly diffusive draw solutes to maximise water flux and those which show low reverse solute flux.

\section{[Figure 2]}

\subsubsection{Reverse solute flux selectivity}

In terms of draw solution replenishment cost and sustainable FO operation, a high RSFS is desirable. However, draw solutions that exhibited high RSFS generally had a correspondingly low water flux due to the effects of ICP (Figure 3). For example, magnesium sulfate had the highest RSFS of 9.01 , but water flux was low $\left(2.18 \mathrm{~L} / \mathrm{m}^{2} \mathrm{~h}\right)$. Interestingly, for most draw solutes investigated here, similar to the correlation between reverse solute flux and diffusion coefficient shown in Figure $2 b$, the water flux also decreased exponentially as the RSFS increased (Figure 3). Sodium acetate and magnesium acetate are the only two exceptions and their flux behaviour appeared to diverge from the trend of the other six draw solutes. Both solutes displayed a sufficiently high water flux $\left(>3 \mathrm{~L} / \mathrm{m}^{2} \mathrm{~h}\right)$ but could also demonstrate suitably high RSFS values. One noticeable difference in behaviour between these two solutes was that magnesium acetate had a larger RSFS than that of sodium acetate due to a lower reverse solute flux. This could be attributed to the larger size of the magnesium cation, since both solutes share the same anion (Achilli et al., 2010). Furthermore, the use of organic ionic draw solutes appeared to benefit FO flux performance, particularly in the case of the acetate anion.

\section{[Figure 3]}

The expected concentration of draw solute within the pre-concentrated wastewater was estimated using Equation 1 (Table 2). Since the simulated concentration only depends on RSFS, solutes with a low RSFS result in larger concentrations, and alternatively, high RSFS ideally lowers the expected concentration. Nonetheless, inorganic salts are known to inhibit anaerobic treatment even at low concentrations (Chen et al., 2008).

\section{[Table 2]}

\subsection{Effect of reverse draw solute flux on anaerobic treatment}

Each draw solute had a noticeable impact on methane production over the 25 day observation period (Figure 4). The substrate characteristics before and after the BMP experiment are 
shown in the Supplementary Data (Table S1). The organic-based draw solutes, namely, glycine, glucose, and the acetates displayed higher cumulative methane production compared to the control (no added draw solute), possibly because they are readily biodegradable. Glycine outperformed all other draw solutes. This might be attributed to its osmoprotectant properties, which can reduce osmotic stress caused by inhibitory constituents present in the digested sludge (Oh et al., 2008). However, due to the low saline environment, enhanced methane production was most likely a result of the relatively high concentration of glycine dosed $(3.46 \mathrm{~g} / \mathrm{L})$. Similarly, even at a lower concentration $(1.48 \mathrm{~g} / \mathrm{L})$, glucose promoted methane production by providing additional organic substrate. Sodium acetate presented a similar methane production to glucose, and only slightly higher than magnesium acetate. The presence of the sodium or magnesium cation appeared not to affect acetate conversion; however sodium acetate $(2.41 \mathrm{~g} / \mathrm{L})$ was dosed at a higher concentration than magnesium acetate $(1.65 \mathrm{~g} / \mathrm{L})$. The results suggest that these draw solutes have a positive effect on methane production and would be suitable when integrating FO with anaerobic treatment.

\section{[Figure 4]}

EDTA disodium salt and sodium formate exhibited a similar cumulative methane production to the control. EDTA disodium salt was expected to enhance methane production by increasing the bioavailability of essential elements (Vintiloiu et al., 2013); however, no additional methane production was observed, possibly because the concentration used in this study was significantly higher than that found to be beneficial by Vintiloiu et al. (2013). The methane production of sodium formate was stable, but occurred at a slower rate compared to that of the control. This could be attributed to the high sodium concentration of $1.8 \mathrm{~g} \mathrm{Na} / \mathrm{L}$, particularly when compared with sodium acetate which contained only $0.7 \mathrm{~g} \mathrm{Na} / \mathrm{L}$. Additionally, the COD contribution of acetate $(1.07 \mathrm{~g} \mathrm{COD} / \mathrm{g})$ is much larger than formate $(0.34 \mathrm{~g} \mathrm{COD} / \mathrm{g})$ and would have promoted a faster and more consistent rate of methane production (Grobicki \& Stuckey, 1989).

Inorganic draw solutes had a negative effect on methane production over the observation period. Sodium chloride had only slight negative effects on methane production, most likely caused by the dehydration of bacterial cells due to osmotic pressure (Chen et al., 2008). This inhibition observed at $2.3 \mathrm{~g} \mathrm{Na} / \mathrm{L}$ is slightly lower than the $3 \mathrm{~g} \mathrm{Na} / \mathrm{L}$ reported to be toxic to methanogenic bacteria (Feijoo et al., 1995). Therefore, the presence of sodium chloride in 
pre-concentrated wastewater by reverse draw solute flux is expected to have a small but discernible effect on anaerobic treatment. Inhibition caused by magnesium sulfate at $1.06 \mathrm{~g} / \mathrm{L}$ was found to be more prominent than sodium chloride. The low methane yield observed for magnesium sulfate was likely due to the competition for substrate between sulfate reducing and methane producing bacteria. Inhibitory concentrations for methanogens have been

reported to be as low as $1.4 \mathrm{~g} \mathrm{SO}_{4}{ }^{2-} / \mathrm{L}$ (Siles et al., 2010) which is in good agreement with the results of this study. Despite other advantages associated with the use of inorganic salts, the use of these draw solutes is not recommended when integrating FO with anaerobic treatment, with current FO membranes.

Independent of the draw solution and reverse solute flux, elevated salt concentrations would be expected in pre-concentrated wastewater due to retention by the FO membrane. In the case of inorganic draw solutions, further inhibition of methane production and inefficiencies in the anaerobic digestion process could be expected. For the organic draw solutions demonstrated to be beneficial for anaerobic treatment, the salinity of the pre-concentrated wastewater would not be significantly exacerbated by reverse solute flux. Furthermore, significantly higher COD concentrations would be achieved during wastewater pre-concentration as a result of the contribution of reverse solute flux, allowing the opportunity to operate at a lower concentration factor.

\subsection{Draw solute suitability for anaerobic treatment}

Sodium acetate and magnesium acetate were two draw solutions that ranked high in terms of FO flux performance. Both exhibited a slightly lower water flux when compared with sodium chloride; however, their reverse solute flux was significantly lower. In FO wastewater applications, a low reverse solute flux is crucial for maintaining flux sustainability, lowering replenishment costs, and reducing salinity build-up. In terms of BMP, glycine demonstrated significant potential for anaerobic treatment. Glucose, sodium acetate, and magnesium acetate were also suitable, as their presence in pre-concentrated wastewater could enhance methane production. Overall, sodium acetate ranked highly in terms of FO flux performance and suitability for anaerobic treatment, as well as providing cost advantages over magnesium acetate in terms of specific cost (Bowden et al., 2012).

Ionic organic draw solutes were found to be the most suitable and therefore further implications exist. Wastewater pre-concentration using an organic-based draw solution is yet 
to be demonstrated. Detailed investigations into flux sustainability, the potential aggravation of organic fouling and compatibility with reconcentration processes are required. As previously mentioned, the retention and accumulation of feed salinity also require further examination, in terms of reducing the osmotic driving force and also the compatibility with anaerobic treatment.

\section{Conclusion}

This study assessed draw solution flux performance and the impact of reverse solute flux on the anaerobic treatment of FO pre-concentrated wastewater. The results show that organicbased draw solutions such as sodium acetate are most suitable for this application, due to the acceptable flux performance and benefits towards methane production. The effects of inorganic salts on anaerobic treatment were also demonstrated. The reverse solute flux of sodium chloride only exerted a small but discernible inhibitory effect on methane production. The BMP test could be a reliable screening tool for assessing draw solution compatibility with anaerobic digestion.

\section{Acknowledgements}

This research was supported under the Australian Research Council's Discovery Project funding scheme (project DP140103864). Scholarship support to Ashley Ansari by the University of Wollongong is gratefully acknowledged.

\section{References}

[1] Achilli, A., Cath, T.Y., Childress, A.E. 2010. Selection of inorganic-based draw solutions for forward osmosis applications. J. Membr. Sci., 364, 233-241.

[2] Bowden, K.S., Achilli, A., Childress, A.E. 2012. Organic ionic salt draw solutions for osmotic membrane bioreactors. Bioresour. Technol., 122, 207-216.

[3] Burn, S., Muster, T., Kaksonen, A., Tjandraatmadja, G. 2013. Resource Recovery from Wastewater: A Research Agenda. Water Environ. Res. Found.

[4] Cath, T.Y., Elimelech, M., McCutcheon, J.R., McGinnis, R.L., Achilli, A., Anastasio, D., Brady, A.R., Childress, A.E., Farr, I.V., Hancock, N.T., Lampi, J., Nghiem, L.D., Xie, M., 
Yip, N.Y. 2013. Standard Methodology for Evaluating Membrane Performance in Osmotically Driven Membrane Processes. Desalination, 312, 31-38.

[5] Chen, Y., Cheng, J.J., Creamer, K.S. 2008. Inhibition of anaerobic digestion process: A review. Bioresour. Technol., 99, 4044-4064.

[6] Eaton, A.D., Franson, M.A.H., Association, A.P.H., Association, A.W.W., Federation, W.E. 2005. Standard Methods for the Examination of Water \& Wastewater. American Public Health Association.

[7] Feijoo, G., Soto, M., Méndez, R., Lema, J.M. 1995. Sodium inhibition in the anaerobic digestion process: Antagonism and adaptation phenomena. Enzyme Microb. Technol., 17, 180-188.

[8] Garcia-Belinchón, C., Garcia-Belinchón, C., Rieck, T., Bouchy, L., Galí, A. 2013. Struvite recovery: Pilot-scale results and economic assessment of different scenarios. Water Practice Technol., 8, 119-130.

[9] Grobicki, A., Stuckey, D.C. 1989. The role of formate in the anaerobic baffled reactor. Water Res., 23, 1599-1602.

[10] Hancock, N.T., Xu, P., Roby, M.J., Gomez, J.D., Cath, T.Y. 2013. Towards direct potable reuse with forward osmosis: Technical assessment of long-term process performance at the pilot scale. J. Membr. Sci., 445, 34-46.

[11] Hau, N.T., Chen, S.-S., Nguyen, N.C., Huang, K.Z., Ngo, H.H., Guo, W. 2014. Exploration of EDTA sodium salt as novel draw solution in forward osmosis process for dewatering of high nutrient sludge. J. Membr. Sci., 455, 305-311.

[12] Iranpour, R., Stenstrom, M.K., Tchobanoglous, G., Miller, D., Wright, J., Vossoughi, M. 1999. Environmental engineering: Energy value of replacing waste disposal with resource recovery. Science, $285,706-711$.

[13] Koch, K., Helmreich, B., Drewes, J.E. 2015. Co-digestion of food waste in municipal wastewater treatment plants: Effect of different mixtures on methane yield and hydrolysis rate constant. Appl. Energ., 137, 250-255. 
[14] Koppelaar, R.H.E.M., Weikard, H.P. 2013. Assessing phosphate rock depletion and phosphorus recycling options. Global Environ. Chang., 23, 1454-1466.

[15] Lutchmiah, K., Cornelissen, E.R., Harmsen, D.J.H., Post, J.W., Lampi, K., Ramaekers, H., Rietveld, L.C., Roest, K. 2011. Water recovery from sewage using forward osmosis. Water Sci. Technol., 64, 1443-1449.

[16] Lutchmiah, K., Lauber, L., Roest, K., Harmsen, D.J.H., Post, J.W., Rietveld, L.C., van Lier, J.B., Cornelissen, E.R. 2014. Zwitterions as alternative draw solutions in forward osmosis for application in wastewater reclamation. J. Membr. Sci., 460, 82-90.

[17] Mayer, F., Gerin, P.A., Noo, A., Foucart, G., Flammang, J., Lemaigre, S., Sinnaeve, G., Dardenne, P., Delfosse, P. 2014. Assessment of factors influencing the biomethane yield of maize silages. Bioresour. Technol., 153, 260-268.

[18] McCarty, P.L., Bae, J., Kim, J. 2011. Domestic Wastewater Treatment as a Net Energy Producer-Can This be Achieved? Environ. Sci. Technol., 45, 7100-7106.

[19] McCutcheon, J.R., Elimelech, M. 2006. Influence of concentrative and dilutive internal concentration polarization on flux behavior in forward osmosis. J. Membr. Sci., 284, 237247.

[20] Nawaz, M.S., Gadelha, G., Khan, S.J., Hankins, N. 2013. Microbial toxicity effects of reverse transported draw solute in the forward osmosis membrane bioreactor (FO-MBR). J. Membr. Sci., 429, 323-329.

[21] Nghiem, L.D., Manassa, P., Dawson, M., Fitzgerald, S.K. 2014a. Oxidation reduction potential as a parameter to regulate micro-oxygen injection into anaerobic digester for reducing hydrogen sulphide concentration in biogas. Bioresour. Technol., 173, 443-447.

[22] Nghiem, L.D., Nguyen, T.T., Manassa, P., Fitzgerald, S.K., Dawson, M., Vierboom, S. 2014b. Co-digestion of sewage sludge and crude glycerol for on-demand biogas production. Int. Biodeterior. Biodegradation.

[23] Oh, G., Zhang, L., Jahng, D. 2008. Osmoprotectants enhance methane production from the anaerobic digestion of food wastes containing a high content of salt. J. Chem. Technol. Biotechnol., 83, 1204-1210. 
[24] Shaffer, D.L., Werber, J.R., Jaramillo, H., Lin, S., Elimelech, M. 2015. Forward osmosis: Where are we now? Desalination, 356, 271-284.

[25] Shannon, M.A., Bohn, P.W., Elimelech, M., Georgiadis, J.G., Marinas, B.J., Mayes, A.M. 2008. Science and technology for water purification in the coming decades. Nature, $452,301-310$.

[26] Siles, J.A., Brekelmans, J., Martín, M.A., Chica, A.F., Martín, A. 2010. Impact of ammonia and sulphate concentration on thermophilic anaerobic digestion. Bioresour. Technol., 101, 9040-9048.

[27] Tang, M.K.Y., Ng, H.Y. 2014. Impacts of different draw solutions on a novel anaerobic forward osmosis membrane bioreactor (AnFOMBR). Water Sci. Technol., 69, 2036-2042.

[28] Verstraete, W., Vlaeminck, S.E. 2011. ZeroWasteWater: short-cycling of wastewater resources for sustainable cities of the future. Int. J. Sust. Dev. World, 18, 253-264.

[29] Vintiloiu, A., Boxriker, M., Lemmer, A., Oechsner, H., Jungbluth, T., Mathies, E., Ramhold, D. 2013. Effect of ethylenediaminetetraacetic acid (EDTA) on the bioavailability of trace elements during anaerobic digestion. Chem. Eng. J., 223, 436-441.

[30] Xie, M., Nghiem, L.D., Price, W.E., Elimelech, M. 2013. A Forward OsmosisMembrane Distillation Hybrid Process for Direct Sewer Mining: System Performance and Limitations. Environ. Sci. Technol., 47, 13486-13493.

[31] Xie, M., Nghiem, L.D., Price, W.E., Elimelech, M. 2014. Toward Resource Recovery from Wastewater: Extraction of Phosphorus from Digested Sludge Using a Hybrid Forward Osmosis-Membrane Distillation Process. Environ. Sci. Technol. Lett., 1, 191-195.

[32] Yong, J.S., Phillip, W.A., Elimelech, M. 2012. Coupled reverse draw solute permeation and water flux in forward osmosis with neutral draw solutes. J. Membr. Sci., 392-393, 9-17. [33] Zhao, S.A.F., Zou, L.D. 2011. Relating solution physicochemical properties to internal concentration polarization in forward osmosis. J. Membr. Sci., 379, 459-467. 


\section{List of Tables}

Table 1: Molar concentration required to generate 30 bar of osmotic pressure and solute diffusion coefficients. Concentrations were calculated using OLI Stream Analyzer.

\begin{tabular}{|l|l|c|c|c|}
\hline \multicolumn{2}{|c|}{ Draw solutes } & $\begin{array}{c}\text { Concentration } \\
(\mathbf{M})\end{array}$ & $\begin{array}{c}\text { Diffusion } \\
\text { coefficient } \\
\left(\mathrm{m}^{2} / \mathbf{s}\right)\end{array}$ & Reference \\
\hline \multirow{3}{*}{ Inorganic } & Sodium chloride & 0.65 & $1.47 \times 10^{-9}$ & (Achilli et al., 2010) \\
\cline { 2 - 5 } & Magnesium sulfate & 1.24 & $3.7 \times 10^{-10}$ & (Achilli et al., 2010) \\
\hline \multirow{4}{*}{$\begin{array}{l}\text { Organic } \\
\text { (ionic) }\end{array}$} & Sodium acetate & 0.72 & $1.44 \times 10^{-9}$ & (Bowden et al., 2012) \\
\cline { 2 - 5 } & Magnesium acetate & 0.84 & $1.14 \times 10^{-9}$ & (Bowden et al., 2012) \\
\cline { 2 - 5 } & Sodium formate & 0.72 & $1.59 \times 10^{-9}$ & (Bowden et al., 2012) \\
\cline { 2 - 5 } & EDTA disodium salt & 0.30 & $5.83 \times 10^{-10}$ & (Lide \& Kehiaian, 1994) \\
\hline \multirow{4}{*}{$\begin{array}{l}\text { Organic } \\
\text { (covalent) }\end{array}$} & Glucose & 1.13 & $6.7 \times 10^{-10}$ & (Yong et al., 2012) \\
\cline { 2 - 5 } & Glycine & 1.31 & $1.06 \times 10^{-9}$ & (Lutchmiah et al., 2014) \\
\cline { 2 - 5 } & Glycerol & 1.27 & $9.3 \times 10^{-10}$ & (Hayduk \& Laudie, 1974) \\
\cline { 2 - 5 } & Urea & 1.26 & $1.38 \times 10^{-9}$ & (Hayduk \& Laudie, 1974) \\
\hline
\end{tabular}

Table 2: Expected draw solute concentration (by reverse solute flux) in pre-concentrated wastewater assuming 90\% FO system water recovery.

\begin{tabular}{|l|c|}
\hline \multicolumn{1}{|c|}{ Draw solute } & Concentration (g/L) \\
\hline Sodium chloride & 5.78 \\
\hline Sodium formate & 5.45 \\
\hline Glycine & 3.46 \\
\hline Sodium acetate & 2.41 \\
\hline Magnesium acetate & 1.65 \\
\hline EDTA disodium salt & 1.52 \\
\hline Glucose & 1.48 \\
\hline Magnesium sulfate & 1.06 \\
\hline
\end{tabular}




\section{List of Figure Captions}

Figure 1: Average water flux, reverse solute flux and RSFS at an osmotic pressure of 30 bar. Error bars represent the standard deviation of duplicate experiments.

Figure 2: Relationship between diffusion coefficient and (a) water flux (linear regression $\mathrm{R}^{2}$ $=0.90$ ); (b) reverse solute flux (exponential regression $\mathrm{R}^{2}=0.81$ ). Experiments were conducted at constant osmotic pressure (30 bar); error bars represent the standard deviation of duplicate tests.

Figure 3: Variation of water flux with RSFS. Experiments were conducted at constant osmotic pressure (30 bar); error bars represent the standard deviation of duplicate tests.

Figure 4: Cumulative methane production of digested sludge with dosed draw solute at concentrations corresponding to FO RSFS and 90\% system recovery; error bars represent the standard deviation of duplicate experiments. 


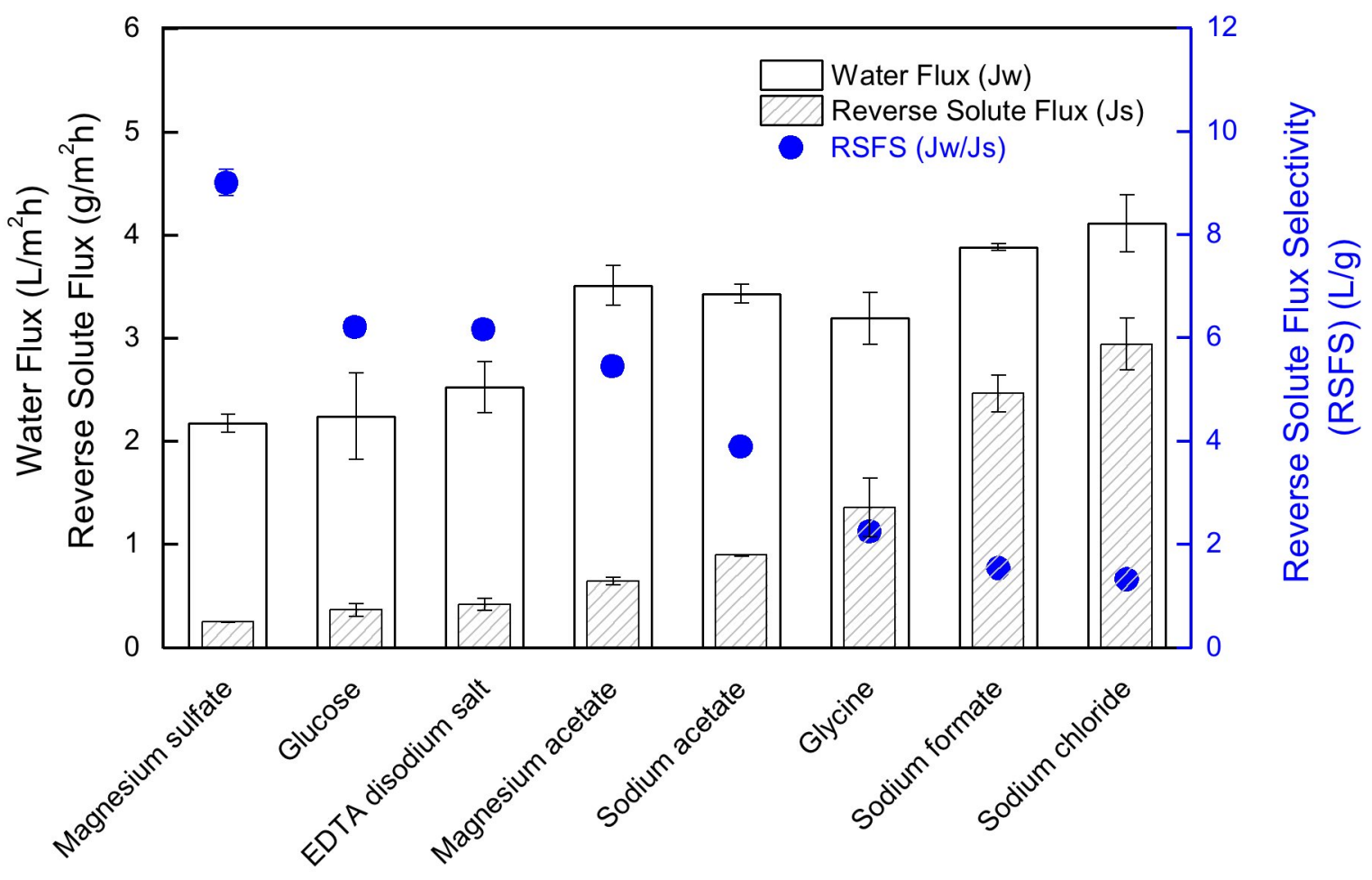

Figure 1 

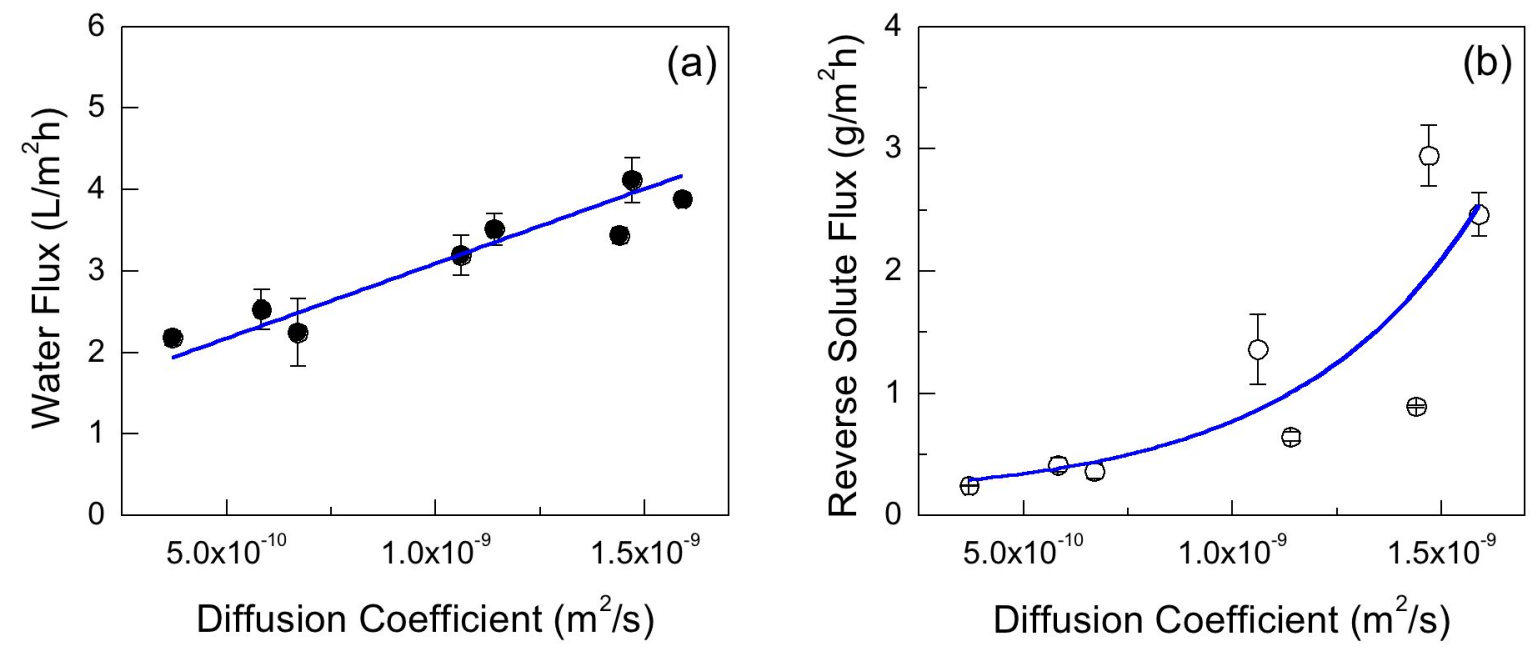

Figure 2 


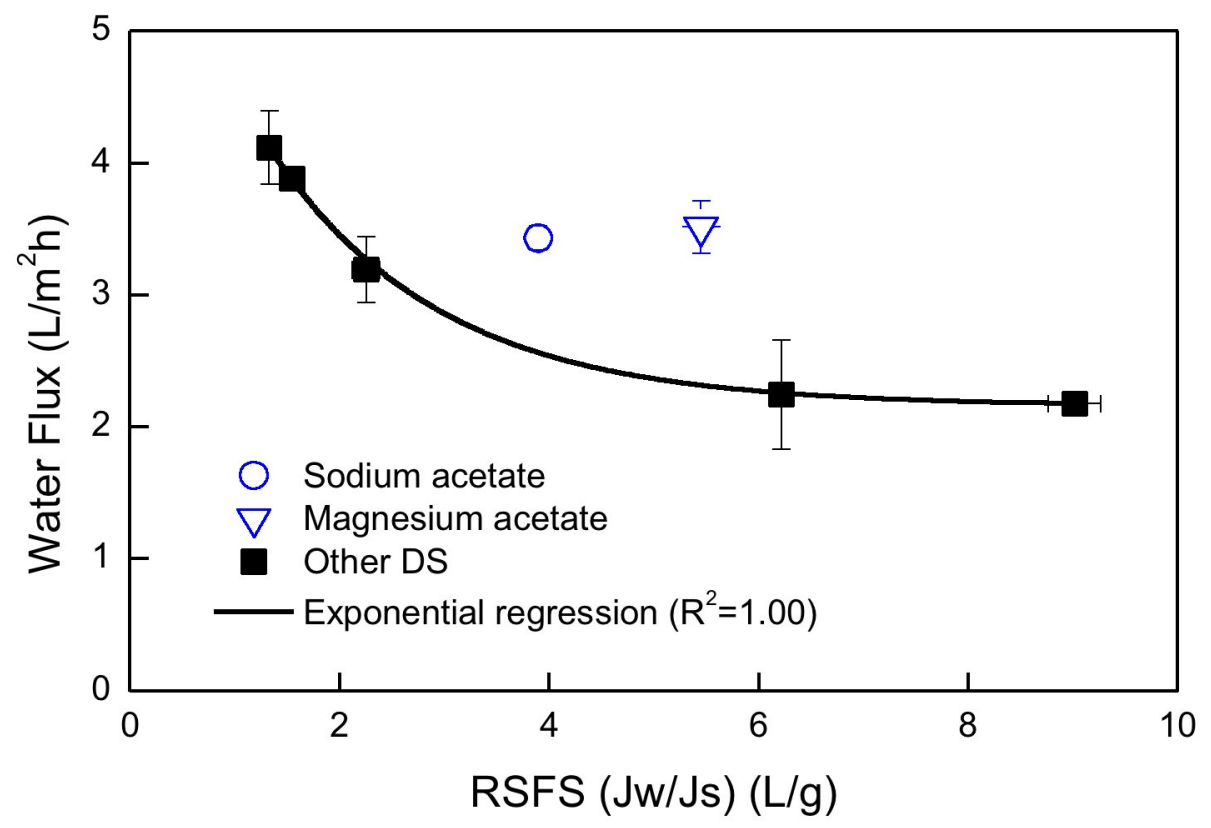

Figure 3 


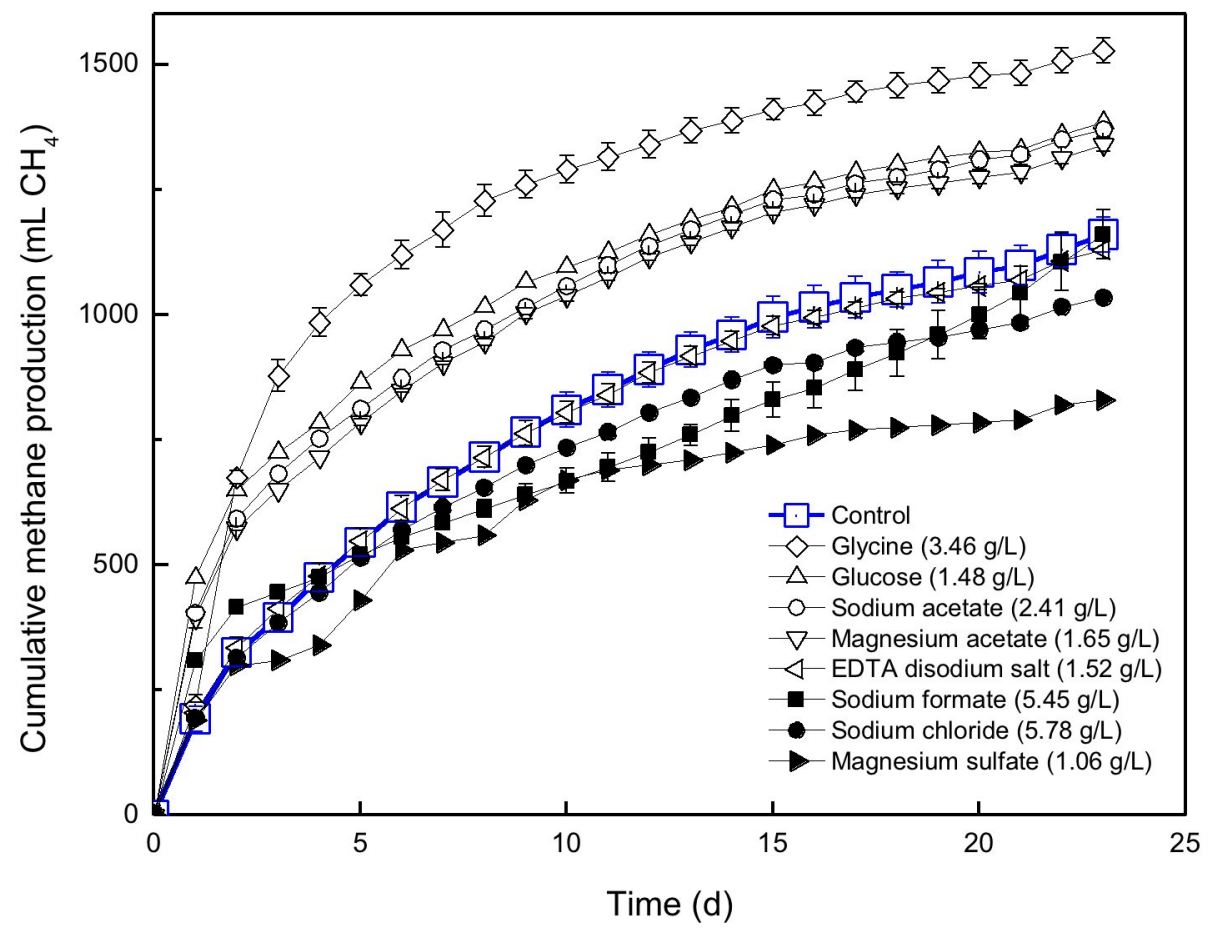

Figure 4 